Article

\title{
Fundamental Principles Ensuring Successful Implementation of New-Age (Nano) Modified Emulsions (NME) for the Stabilisation of Naturally Available Materials in Pavement Engineering
}

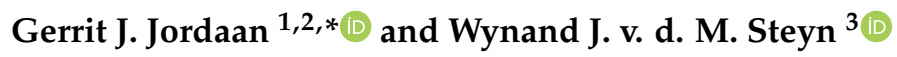 \\ 1 Department of Civil Engineering, University of Pretoria, Hatfield, Pretoria 0002, South Africa \\ 2 Jordaan Professional Services (Pty) Ltd. t/a JPS, Pretoria 0002, South Africa \\ 3 Department of Civil Engineering, School of Engineering, University of Pretoria, Pretoria 0002, South Africa; \\ wynand.steyn@up.ac.za \\ * Correspondence: jordaangj@tshepega.co.za; Tel.: +27-824-164-945
}

check for

updates

Citation: Jordaan, G.J.; Steyn, W.J.v.d.M. Fundamental Principles Ensuring Successful Implementation of New-Age (Nano) Modified Emulsions (NME) for the Stabilisation of Naturally Available Materials in Pavement Engineering. Appl. Sci. 2021, 11, 1745. https://doi.org/ 10.3390/app11041745

Academic Editor: Luís Picado Santos

Received: 26 January 2021

Accepted: 8 February 2021

Published: 16 February 2021

Publisher's Note: MDPI stays neutral with regard to jurisdictional claims in published maps and institutional affiliations.

Copyright: (c) 2021 by the authors. Licensee MDPI, Basel, Switzerland. This article is an open access article distributed under the terms and conditions of the Creative Commons Attribution (CC BY) license (https:// creativecommons.org/licenses/by/ $4.0 /)$.
Featured Application: Providing road transportation infrastructure using traditional design methods and materials comes at a considerable cost. The use of naturally available materials using New-age Modified Emulsions (NME) has been successfully implemented and tested. Proven material compatible nanotechnologies enhancement of materials, incorporating modern material sciences can considerably reduce the unit costs of road infrastructure and improve basic service delivery. However, the successful implementation of these new nanotechnology solutions depends on the assessment and scientific evaluation of various factors that will ensure success of implementation as addressed in this paper.

Abstract: Good transportation systems are pre-requisites to economic development. Empirically developed, archaic test methods are traditionally used for materials classification used in road construction. This system normally classifies naturally available materials subjected to chemical weathering conditions, as unsuitable for use in the load-bearing road pavement layers. Consequently, design standards normally require the use of imported materials at considerable costs, severely restricting road network development under scenarios of limited funding. The introduction of applicable nanotechnologies has been shown to enable the use of naturally available materials in all pavement layers at a substantial reduction in costs. The successful roll-out of these nanotechnology solutions depends on a sound, scientifically based approach. Aspects such as toxicity, health and safety, etc. must be addressed in a holistic approach together with material compatibility and fundamental engineering requirements. The successes achieved over the last decade, introducing material compatible New-age Modified Emulsions (NME), are based on fundamental concepts that need to be considered in a holistic test, evaluation and implementation strategy. This paper identifies fundamental concepts related to nanotechnology implementation in the context of road pavement engineering, which needs to be addressed to ensure successful implementation. Ad hoc implementation of new-age technologies without adequate scientific evaluation could prove detrimental.

Keywords: nanotechnologies; pavement engineering; scientific principles; material compatible design; mineralogy; safety; applicability; compatibility; new technologies; engineering principles

\section{Introduction}

Silicon-based new-age nanotechnology products have been used in the built-environment since the early 1800s. At the time, scientists were tasked in Europe with the challenge to develop products to protect stone buildings, monuments and statues from deterioration due to the observed detrimental effect of water and pollution [1]. Conflicting results by 
various scientists soon led to the conclusion that the type of stone and the condition of the stone, play an important part in the successful use of a specific silicon-based product to be effective and achieve the required results. These conclusions were derived after decades of testing using a trial-and-error approach. The development of advanced investigation and observation equipment (such as the Atomic Force Microscope (AFM)) in the 1980/1990s enabled scientists to observe and manipulate the behaviour of nano-size particles which led to the science of nanotechnology, influencing basically all major industries [2,3].

It follows that since the 1980s, the science of new-age nanotechnology products for use in the built environment have developed exponentially. These products are used throughout the industry to, inter alia, enhance and protect of all types of building products, including wood, gypsum-board, etc., as well as the relatively softer and vulnerable type of building blocks such as sandstone, limestone and marble. These products are widely used in the built environment mostly incorporate silicon as a basic element that exhibits "excellent mechanical, optical, thermal and electrical properties" [4].

Most of the naturally available materials found in global climatic zones that are subjected to weathering due to chemical decomposition (high temperatures associated with seasonal rainfall [5]) are classified by road pavement engineers as marginal or unsuitable for use in the load bearing layers (upper layers) of a road structure. This "unsuitable" classification is mainly due to the risk associated with the secondary minerals (e.g., clays, etc.) that are present due to chemical decomposition of the primary minerals. The same nanotechnology silicon-based products used in the built environment can also be utilised to change this scenario. These naturally available materials can be treated, enhanced, stabilised and the secondary minerals neutralised to enable these materials to be used in the load bearing layers of a pavement structure [6]. Testing has shown the potential of such stabilisation of materials of unsuitable quality for use on roads carrying low to relatively high traffic loadings (in excess of 30 million dual wheel standard $80 \mathrm{kN}$ axle loads $(\mathrm{E} 80 \mathrm{~s}))[7,8]$. These examples, have also shown that the use of nano-silane technologies, enabling the use of naturally available materials without comprising the integrity the road pavement structures, could result in the reduction of the unit costs of surfaced roads by 30 to 50 per cent or more. These savings are influenced by various factors, such as the availability and proximity of high-quality crushed stone, traditionally used in the upper structural layers of a road.

Many alternative "wonder" products have been introduced onto the market to improve naturally available materials for use in roads over many a decade. These products were mostly based on a limited number of empirically based tests of a few selected materials. Invariably, these products did not meet expectations. As a result of these experiences, the engineering fraternity developed a scepticism and resistance towards the introduction of new technologies. It follows that any new-age nanotechnology needs to be based on a sound scientific basis to limit the risks associated with new products. A scientific approach also requires that material testing be extended to include the scientific analysis of the mineralogy of the materials in order to determine the primary and secondary minerals that need to be accounted for $[6,9]$.

New-age nanotechnology products offer significant advantages to the roads industry when introduced based on scientific analysis. This paper identifies the fundamental principles required for the evaluation, application and successful use of new-age nanotechnologies in pavement engineering, enabling the cost-effective use of naturally available materials in all the pavement layers of the road structure. A design process based on sound scientific principles also need to ensure that basic principles in terms of safety and responsible engineering in terms of environmental impact be met. The paper aims to identify the major factors associated with the introduction of nanotechnology solutions in pavement engineering that will ensure that design approaches are developed that, as far as possible, ensures that pavement engineers adhere to the core of their profession, i.e., to optimise the use of available resources (including available funds) with a minimum associated risk. Considerable benefits can be realised when these new technologies (e.g., nanotechnologies) 
are used in a responsible scientifically based approach to deliver macro infrastructure projects (e.g., surfaced road infrastructure) through the enhancement of naturally available materials with less associated environmental damage, low required maintenance and hence, a considerable reduction in life-cycle costs [10].

\section{Objectives: Addressing Engineering Resistance to Change and Establishing Principles}

The road pavement engineering fraternity is known for its conservative approach, still relying to a large extent, on empirically derived, material characterization tests developed in the early 1900's. The characterization of naturally available materials has been a contentious issue between pavement engineers and geologists (who prefer a scientifically based mineralogy approach) in various countries since the 1950s [5]. In addition, pavement engineers have also been inundated over the last few decades with "wonder products" that have been introduced into the market, claiming that it is able to solve all material related problems. These products have no scientific basis, are usually accompanied with limited empirically derived test results and invariably proved disastrous in practice.

As learnt by the built environment, the successful application of available nano-silica products to improve and protect stone, depends on the "type of stone" and the "condition of the stone" [1]. It follows that the successful introduction of available, proven nano-silane products into pavement engineering to improve and protect naturally available materials, will depends, as a minimum, on a scientific material classification system. In addition, test methods have to be introduced which are representative of basis required engineering physics in terms of stresses, stains and durability.

Any success achieved through the introduction of nano-silane products, will invariable be followed by salesmen claiming, "to have the best products" and the reintroduction of "wonder products". In order to counter these claims, it is essential that the pavement engineer in practice, be provided with basic guidelines for the assessment of any product and the major principles that need to be proven by any manufacturer/supplier in terms of basic engineering properties and scientifically based criteria. The objectives of this paper are firstly to ensure that the major aspects to be addressed by pavement engineers are put in place in order to design and introduce nano-silane products that will prove successful and cost-effectively in practice. Secondly, the introduction of these fundamental principles should also ensure that any "wonder product" be timeously eliminated before practical implementation and costly, premature failures.

\section{Basic Principles for a Design Approach to Successfully Incorporate New-Age Nanotechnologies in Pavement Engineering and Reduce Design Associated Risks}

The understanding of the benefits to be gained and the principles associated with the use of new-age nanotechnologies are crucial to the successful introduction thereof in the roads industry. General concerns in terms of issues such as health and safety need to be addressed. The need for a scientific basis to ensure the successful use of materials traditionally considered to be sub-standard for use in the load bearing upper layers of a pavement structure need to be understood as crucial in an industry known for a conservative approach to change. Hence, the benefits and the positive effect thereof in terms of cost-effective service delivery, incorporating scientific principles in design are identified and explained while, important aspects are highlighted. The general adoption of new technologies is closely linked to the ease of application, not requiring complicated procedures (e.g., the introduction of new telecom (cellular phones) and IT devices (laptops)).

The same principles will apply to the introduction of new technologies in the roads industry. Design methods must ensure that the risk associated to construction processes are reduced (this is ensured by following a scientifically based design process). In addition, any materials used in the construction process must be conducive to construction procedures applicable in a sophisticated, as well as a developing environment. Developing countries usually have severe challenges when introducing materials with very limited onsite stability and/or requiring special equipment for implementation and/or complicated 
processing procedures. Ultimately, all of these aspects will have to be separately addressed in special construction specifications aimed at specific end-product specifications, allowing competition on an equal basis while eliminating products not meeting or adhering to the basic requirements.

Road unit costs need to be reduced for the developing world to provide the transport infrastructure needed to become economically competitive [6]. New-age Modified Emulsion (NME) stabilisation, successfully introducing nano-silane technologies in the road industry, can be a game changer to this effect, if successfully introduced. The following fundamental basic characteristics associated with available, proven and/or new nanotechnologies in association with suitable stabilising agents in a scientifically based design approach in pavement engineering, will ensure that risks are minimised through the introduction of these technologies in the road environment [6]:

- Toxicology, health and safety of the use of various nano-scale products;

- Environmental aspects, leaching and affecting ground water;

- Nanotechnology as a binder;

- Stability of the nano-modified stabilising agent in a carrier fluid, e.g., construction water;

- Quantity (volume) of the nano-silane to be added as influenced by the relative surface area or coverage needed to achieve the required water-resistance characteristics of the material to be stabilised (which influences in-situ durability by eliminating continued chemical de-composition of the naturally available material within the road structure);

- Hydrophobic characteristics as required with the addition of the nano-silane to the naturally available materials;

- Compatibility aspects of nano-silicon modifications to binders that will influence the successful application and use thereof, including;

- Compatibility with the mineralogy of the materials, and

- Compatibility with the stabilising agent to be modified;

- Engineering evaluation of the effect of nano-silicon modifications in terms of required scientific properties (i.e., compressive strengths, tensile strengths and durability), and

- Cost-aspects associated with the use of nanotechnology-based products.

\section{Factors Affecting the Successful Introduction of New-Age Nanotechnologies in Pavement Engineering}

\subsection{Toxicology, Health and Safety}

Concerns about toxicology, dangers to health and safety and environmental influences (e.g., leaching into the sub-strata and affecting the quality of ground water), need to be addressed from the onset with the use of any product (new or traditional). The fact that products have been in use for decades, do not exonerate them from any responsibility and liability towards health and safety aspects.

Two chemical processes are usually applicable with the addition and use of nano-scale products during mixing with a carrying fluid and construction, i.e., a process of hydrolysis when mixed with the carrying fluid (e.g., mixing with water) and condensation (when the product attaches to the material during treatment or stabilisation). During any of these processes by-products can be formed. It must be ensured that any nano-scale product used, does not generate any by-product (liquid or gas) that may be toxic in any way. It is a fact, that the majority of organo-functional silanes are not suitable for general application and can be harmful to life-forms and to the environment. Silanes such as $\mathrm{SiH}_{4}$ and siliconhydrides $\left(\mathrm{R}_{-} \mathrm{SiH}_{3}\right)$ and silicon-halides are "toxic, volatile and generate hydrogen gas during hydrolysis" [1], the effect of which is shown in Equation (1).

$$
\text { Hydrolysis: } \mathrm{SiH}_{4}+4 \mathrm{H}_{2} \mathrm{O}=\mathrm{Si}(\mathrm{OH})_{4}+4 \mathrm{H}_{2}
$$

Other reactive groups involving fluorine $(\mathrm{F})$ and chlorine $(\mathrm{Cl})$ also form volatile and dangerous acids under hydrolysis, such as hydrofluoric and hydrochloric acids that are 
also detrimental to the various mineral groups and are not suitable to be used as stone consolidants [1]. Similarly, in combination with carbon (C), reactive groups containing chlorine $(\mathrm{Cl})$ can produce chloroform $\left(\mathrm{CHCl}_{3}\right)$ as a by-product during the hydrolysis (during mixing with water) or during the consolidation process (when attaching to the material), which is generally difficult to detect, but dangerous and even fatal when applied in confined areas or under conditions with low or no wind-speeds.

In comparison, alkoxy-silanes (also referred to as organo-functional silanes) have low vapour pressures and do not form toxic gasses or acids during hydrolysis. It follows that the requirement of a health and safety toxicology report (Safety Data Sheet) should be a pre-requisite when considering the use of an appropriate nano-silane product for general application.

The by-product formed during the hydrolysis process of the nano-silane when in contact with water, is of fundamental importance in the selection of an appropriate and applicable nano-silane to be used, in general engineering projects [6]. The most appropriate and designed alkoxy-silanes will form water as a by-product or at the worst, a non-corrosive alcohol [1].

Many silane couplings, which are freely available commercially, will form siloxane bonds. However, of these, only a few known nano-silanes will have the "correct balance of volatility and reactivity without being harmful to society" or to the materials being treated [1]. The engineering fraternity need to ensure that applicable chemically based test procedures are in place to verify that no toxic by-products are generated during the construction process (or specify limitations of use when known dangerous by-products are generated (e.g., toxic fumes during the high temperature application of some traditionally used construction materials)). All products (including traditionally used construction products) need to be pre-evaluated and certificated on an equal basis, prior to approval for use in any construction process.

\subsection{Environmental Aspects_Leaching and Groundwater}

During the consolidation process in contact with the stone/gravel/soil, the alkoxysilane is bound to the sub-strata through a Si-O-Si bond (in the case of silicon rich materials), one of the strongest in nature. Using naturally available materials containing few or no free silicon elements to effect silicon bonds (e.g., calcretes or severely weathered laterites), an applicable Hydroxy Conversion Treatment (HCT) [1] nano-product should be added to the compatible nano-silane, ensuring that chemical bonds of similar strengths are achieved. Hence, designed nano-silanes based on the mineralogy of the material will attach to the naturally available materials through "permanent" bonds [6] with no risk of leaching and/or contamination. In fact, the alkoxy-silane modification of traditionally used binders, such as bitumen (as contained in, e.g., bitumen emulsions), will firmly attach the bitumen to the stone/aggregate/soil, preventing any bitumen from detaching from the soil and cause any contamination. It follows that the modification of bitumen or emulsions, using a material compatible nano-silane product, will help to minimise or prevent any possible contamination of the binder to be used.

\subsection{Nano-Silane Technology as a Binder}

Alkoxy-silanes have been shown to be effective as stone preservatives following a process of hydrolysis and condensation $[1,6]$. These functional molecules are typically as small as a few nano-meters in size. This logically limits its ability to effectively bridge gaps and bind together stone/aggregate/soil particles with gaps exceeding that of a three-dimensional gel formed during the consolidation phase of the alkoxy-silane treatment. This bridging distance is usually limited to a maximum distance of between 10 and $60 \mu \mathrm{m}$ [1].

In terms of practical road pavement engineering, granular materials are graded in terms of aggregate sizes varying from $63 \mathrm{~mm}$ to less than $0.075 \mathrm{~mm}$ fractions. It follows that applicable nano-silane technologies have considerable limitations in being used as 
a soil/material stabilising agent on its own. However, at these fractions the non-reactive $\mathrm{Si}-\mathrm{CX}$ or Si-(R) bond (similar to that of an emulsifying agent) of the alkoxy-silane (which is added to the stabilising agent such as bitumen emulsion or equivalent), embeds itself firmly into the bitumen molecule [6]). When the modified bitumen emulsion is added to the aggregate the reactive bonds of the silicon molecule, attaches the bitumen firmly to the minerals in the aggregate (Figure 1).

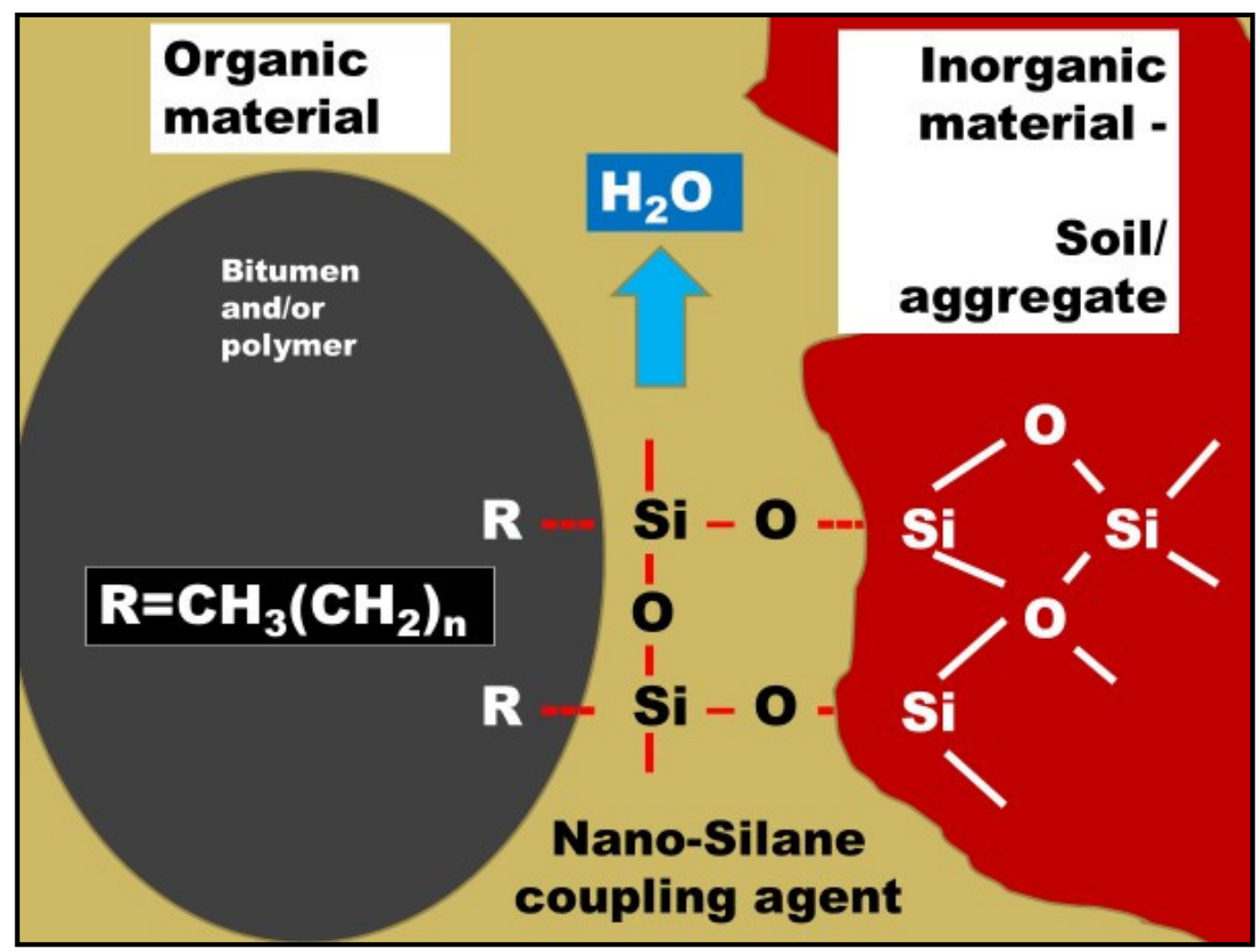

Figure 1. Nano-silane modification to an organic material (bitumen in bitumen emulsion or equivalent) acting as an aggregate adhesive and water repellent.

In practice, the alkoxy-silane modification to traditional stabilising agents such as bitumen emulsions, acts as an effective aggregate adhesive. In addition, it also changes the surface of the stone/aggregate/soil to be hydrophobic. Water is actively being pushed out of the pavement layer and the minerals in the layer are denied access to water molecules, with significant benefits in terms of the future prevention of weathering due to chemical decomposition (the presence of water is a pre-requisite for chemical decomposition of naturally available materials [5]).

\subsection{Stability of the Nano-Scale Modification Stabilising Agents}

The stability of any stabilising agent to road building materials is of fundamental importance, when dealing with projects influenced by variations in conditions beyond the control of the contractor, such as weather, political influences (e.g., labour unrest) and projects in remote areas with access limitations. It is essential to clearly specify and have knowledge about any limitations with regard to the use and storage of any modified stabilising agent. The physics of the stability of nano-size particles are controlled by the physics of basic science. Particles in a carrier fluid are subjected to gravitational forces. When suspended in a carrier fluid, particles are continuously subjected to forces imposed on each particle due to the collisions caused by the fast-moving molecules of the carrier fluid called Brownian movements [11]. The true meaning of Brownian movements and the influence thereof on particle movement were only fully explained by Einstein in 1905 [12]. 
Physics dictate that particles of a nano scale will stay in suspension due to the fact that the forces caused by the Brownian movements exceeding that of gravitational forces as demonstrated in Figure 2.

\section{Stability in carrier fluid (water)}

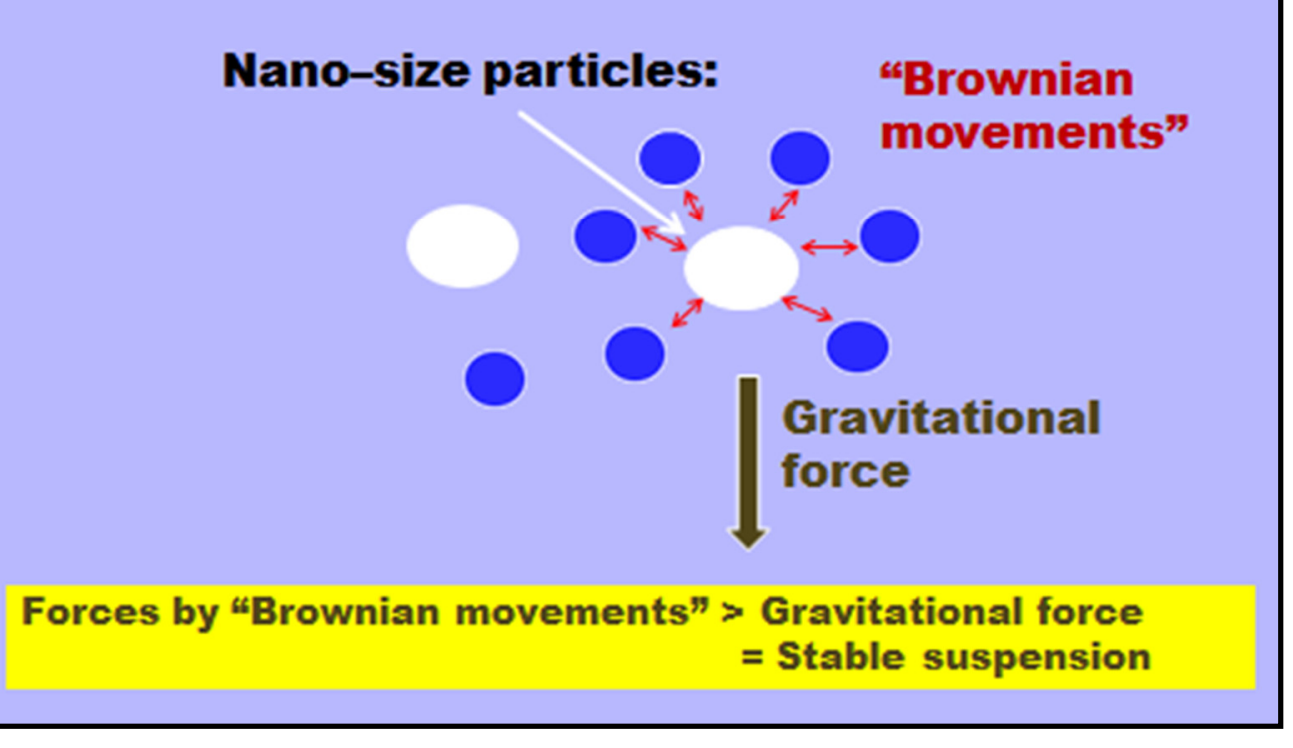

Figure 2. Demonstration of the stability of nano-scale technologies in a water carrier fluid.

It follows that a nano-scale alkoxy-silane as manufactured and delivered in containers, will remain stable and effective as long as it is not placed in contact with an ingredient that will cause a reaction with the reactive compounds of the organo-functional silanes.

When the nano-silane is added as a modifier to an emulsion, the "weakest" chemical bond will determine the stability of the mix. For example, when used as a modifier to a bitumen emulsion the weakest bond within the bitumen emulsion will be of crucial importance when assessing the stability of the modified emulsion [6]. The stability of bitumen emulsions is a function of various factors, including [6], e.g., the type of emulsion (which is a function of chemical bond strengths), the manufacturing process and the type of emulsifying agent. The most effective way to address product stability on-site is to address it through and "end product specification", requiring the supplier to guarantee a minimum stability (e.g., four months) on site to allow for all unforeseen circumstances.

\subsection{Surface Area or Coverage and Volume of Alkoxy-Silane Modifications}

Nanotechnology consists of the use of very small particles or functional molecules measured in nano-meters. The resultant effect is a high ratio achieved in terms of the area covered by a relatively small volume of the nano-product. The surface-area increases dramatically with a decrease in dimension. This aspect is visually demonstrated in Figure 3 [13] where it is shown that the surface area of $1 \mathrm{~kg}$ of particles of a size $1 \mathrm{~mm} \times 1 \mathrm{~mm} \times 1 \mathrm{~mm}$ is equal to $1 \mathrm{mg}$ of the same particles of dimensions of $1 \mathrm{~nm} \times 1 \mathrm{~nm} \times 1 \mathrm{~nm}$. 


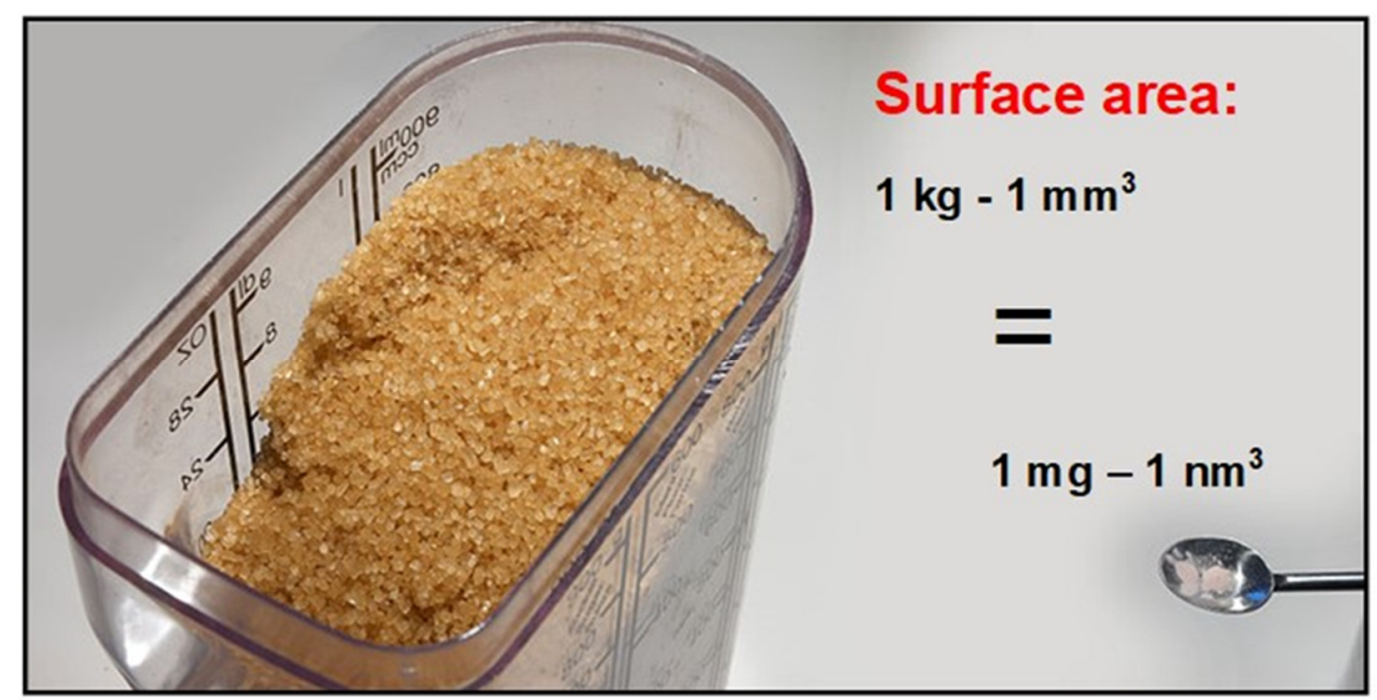

Figure 3. Comparative surface area versus reduction in dimensions [13].

A comparative equivalent measurement in terms of pavement engineering, is that the coverage of about 1000 litres of bitumen with a particle size of about $4 \mu \mathrm{m}$, will be equivalent to 1 litre of nano particles the size of $4 \mathrm{~nm}$. The considerable differences in area versus dimension, will naturally have a meaningful influence on the affordability of a modification using a nano-scale particle. A relatively expensive modification using an effective alkoxysilane, could have a relatively small influence on the cost of the modified binder.

\subsection{Hydrophobic Characteristics of an Alkoxy-Silane Modification and/or Treatment}

The treatment of stone/aggregate/soil using an alkoxy-silane or alkoxy-silane modified binder changes the surfaces of the material to become hydrophobic as shown in Figure 1. The power of the hydrophobic (water repellent) effect achieved is directly related to the size of the alkyl group attached to the silicon atom [1]. The water-repellent nature of material is usually observed through a beading effect [14], which is measured by the contact angle of the water with the material (Figure 4).

When the contact angle is less than $90^{\circ}$ the material will be subject to water ingress and a positive absorption will be observed with time, resulting in capillary rise. Material samples placed in water will show a wetness of the material appearing above the waterline, showing a positive water absorption rate ( $\operatorname{Cos}$ of the angle $(\theta)$ is positive between 1 and 0$)$. When the contact angle is between $90^{\circ}$ and $180^{\circ}$, the material is hydrophobic, not allowing water to penetrate the material. Samples of the material placed in water will show no wetness above the water line, indicating a negative capillary rise (Cos of the angle $(\theta)$ is negative between 0 and -1 ). The practical pavement engineering effects of the hydrophilic and hydrophobic effects and capillary rise, caused by the nano-silane modification of bitumen emulsion stabilisation of materials, are shown in Figure 5a,b. 


\section{Water repellent: Beading effect}

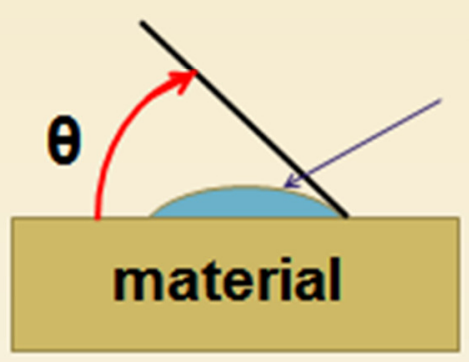

$$
\theta=0^{\circ}-90^{\circ}
$$$$
\operatorname{Cos} \theta=1 \text { to } 0
$$
Hydrophilic

\section{Positive capillary rise}

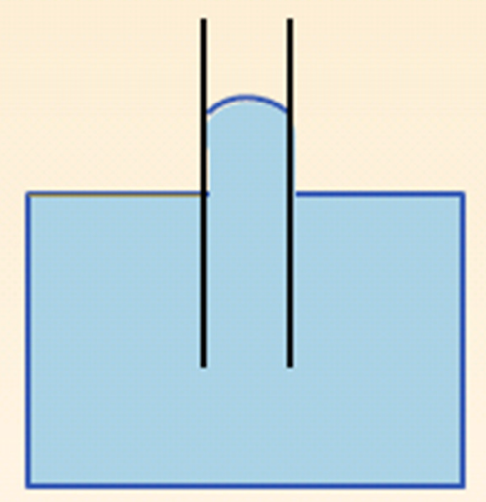

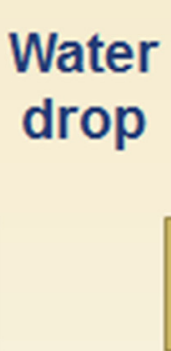

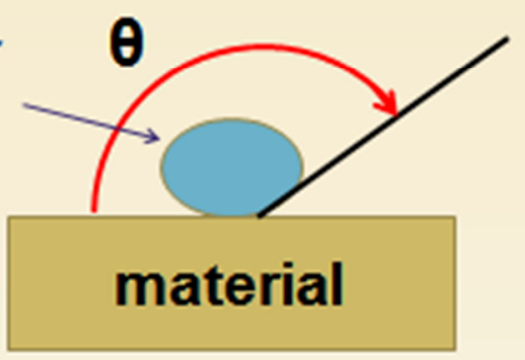

$\theta=90^{\circ}-180^{\circ}$

$\operatorname{Cos} \theta=0$ to -1

Hydrophobic
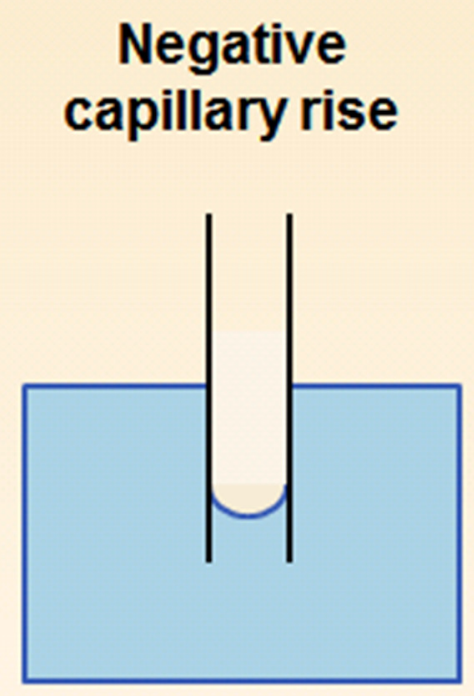

Figure 4. Beading effect: illustrating the hydrophobic (water repellent) nature of a material indicating the water-repellent nature of the material. 


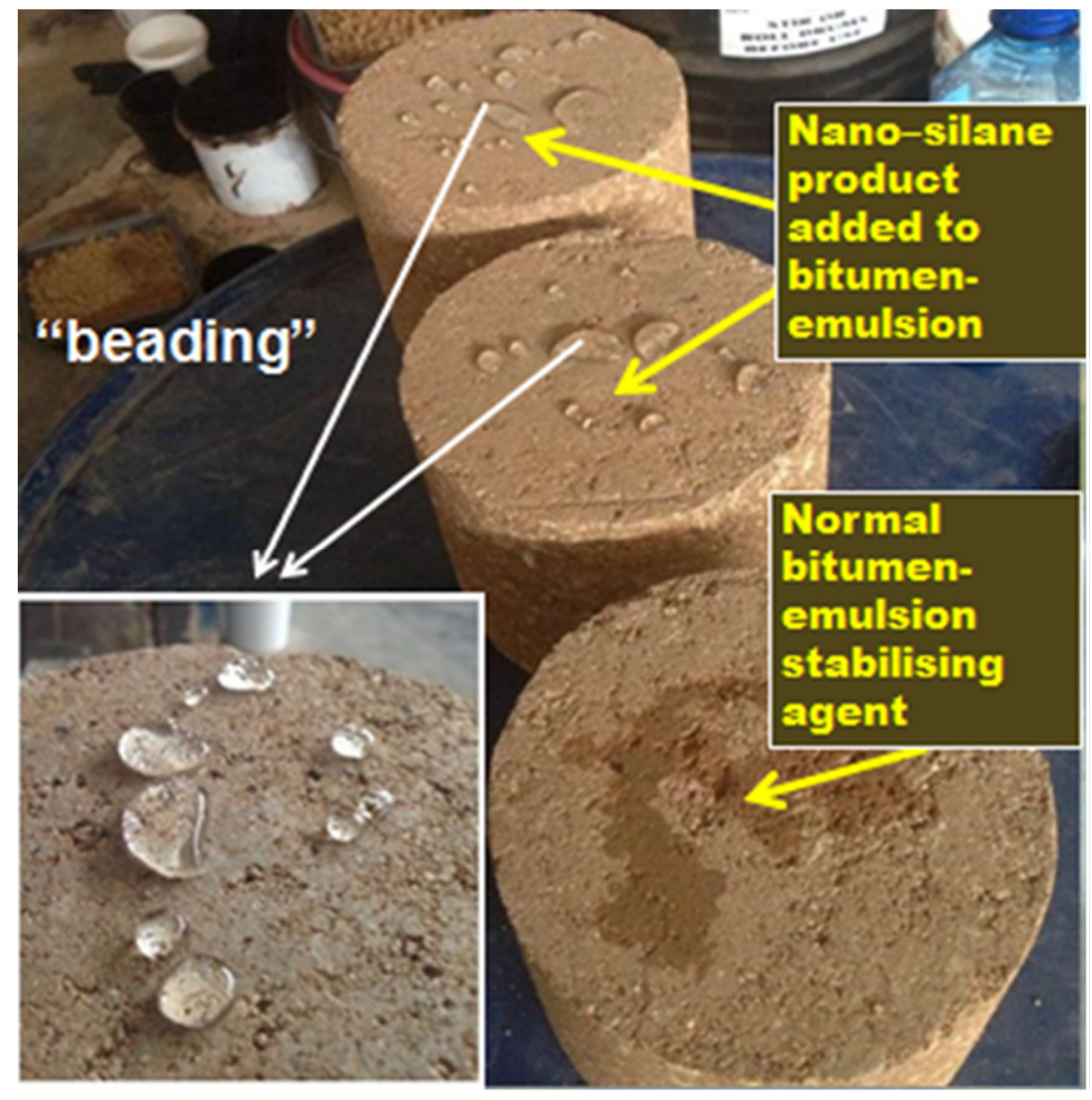

(a)

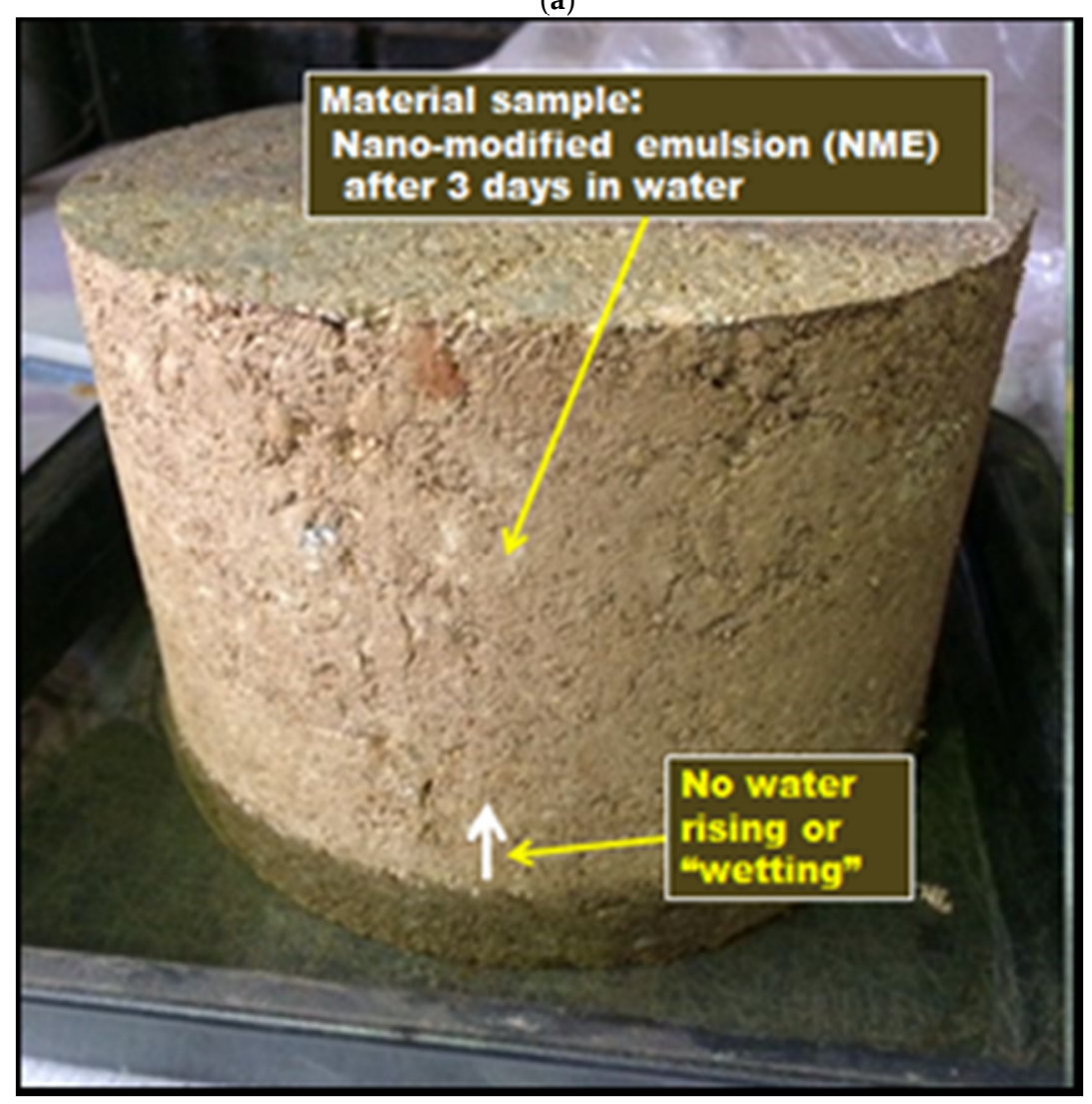

(b)

Figure 5. Beading effect (hydrophobic) in (a) indicating the water-repellent nature of nano-silane modification of bitumen emulsion and the negative capillary rise shown in (b) resulting from the nano-silane modification [15]. 
4.7. Compatibility Aspects of Alkoxy-Silane Modifications to Binders That Will Influence the Successful Application and Use Thereof

\subsubsection{General}

As previously mentioned, alkoxy-silane modifications are designed to attach firmly to the minerals present in the stone/aggregate/soil to form (for example), strong Si-O-Si bonds. This example logically assumes that silicon atoms are present in large quantities in the stone/aggregate/soil that is being treated. Although this assumption applies to a large percentage of the crust of the earth, this is not always correct and the principle inherent in this assumption, cannot be uniformly applied, especially when using highly weathered materials. The applicability of the alkoxy-silane modification not only depends on the primary minerals comprised of the stone/aggregate/soil, but also to the condition of the stone/aggregate/soil (weathering due to chemical decomposition) quantified by the presence of secondary minerals [9]. It follows that the applicability and expected behaviour of any nano-modification of a stabilising agent, will depend on a detailed analysis of the mineralogy of the material. Enough detail must also be obtained to enable the identification of the chemical decomposition that is already present in the material under specific climatic conditions [9].

As discussed previously, alkoxy-silane treatments alone will not be effective to fulfil the normal role of a stabilising agent when treating stone/aggregate/soil. A larger molecule is required to act as a binder bridging the gaps between the stone/aggregate/soil particles. This immediately points to another important aspect related to the applicability of the nanotechnology product to be used, i.e., compatibility with the stabilising agent (such as bitumen emulsion or equivalent) to which the nano-particle (in this case alkoxy-silane or HCT-modified alkoxy-silane as an aggregate adhesive) needs to attach. It follows that the applicability or compatibility of an alkoxy-silane is affected by both the (Figure 1):

- Mineralogy with which it is to be firmly bonded;

- Characteristics of the stabilising agent, the bitumen emulsion and/or compatible polymers(s) to which it is added as a modification.

\subsubsection{Compatibility with the Mineralogy of Materials}

Some available nano-silane products are indeed only effective in the presence of large quantities of silica and have severe limitations in the presence of secondary minerals. It follows that any mineralogy investigations need to determine both the primary as well as the secondary minerals present in naturally available materials to ensure that the most applicable alkoxy-silane or HCT-modified product is applied to the available materials. This requirement is a basic pre-requisite to the successful application of any applicable nano-scale product, to be successfully applied as a modification to any stabilising agent used in material design in pavement engineering $[16,17]$. The influence of minerals in the successful application of nano-silane products as protective coatings of various stone types was already recognised in the 1800's [1,18]. For example, at the time, the application of silica-ester to acidic materials was observed to result in the successful formation of a protective gel while an alkaline sub-stratum will result in the formation of a "useless" gel when treated with silica-ester [18].

It is of importance to note that at the most basic of geology terms, materials can be classified as either acidic, i.e., silicon-based minerals or basic, i.e., calcite that forms the basis of carbonate $\left(\mathrm{CaCO}_{3}\right)$ (alkaline) based minerals. Acidic rocks are normally considered to contain in excess of 50 per cent of acid components, i.e., $\mathrm{SiO}_{2}$ and $\mathrm{CO}_{2}$ [5]. In the absence of silicon and the presence of calcite minerals, different nano-silicon technologies need to be applied.

For example, calcite forms few if any hydroxyl (HO) groups with which alkoxy-silanes can react to form bonds (Figure 1). Hence, complementary nanotechnologies have to be added with stone/aggregate/soils exhibiting high percentages of calcite. The problem with a lack of $\mathrm{HO}$ groups on the surface particles of materials can be resolved by chemically altering the surfacing of the material using approaches such as a Hydroxy Conversion 
Treatment (HCT) [19]. The HCT will convert the surface of a crystal of calcite to produce hydroxyl $(\mathrm{OH})$ groups (Figure 6a) that facilitates alkoxy-silane bonds. The chemical combination of the alkoxy-silane with the HCT and alkaline sub-strata to for a hydrophobic surface, expelling water as a by-product, is demonstrated in Figure 6a-d.

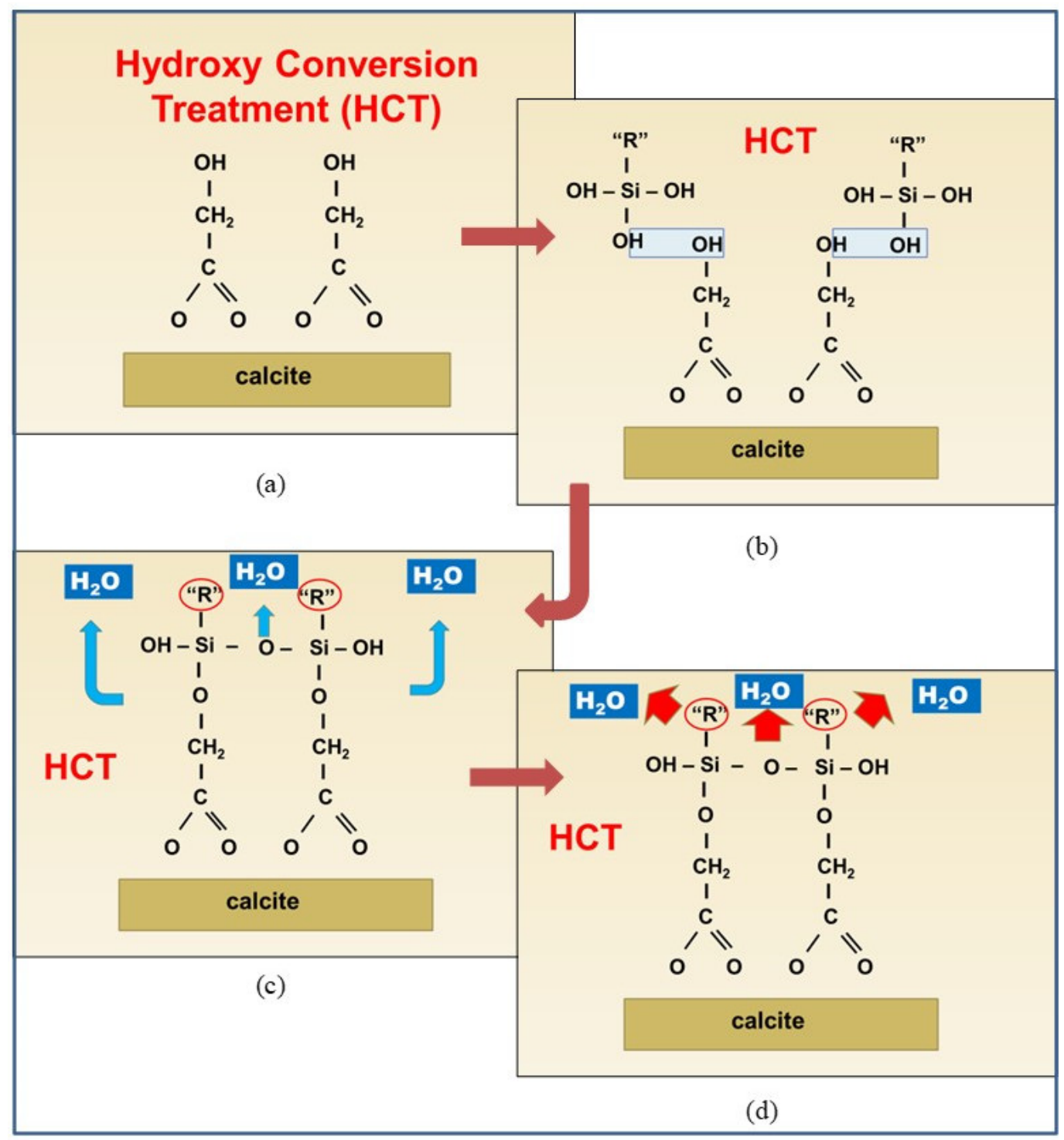

Figure 6. Treatment of calcite sub-strata with a Hydroxy Conversion Treatment (HCT) to create hydroxyl groups for nano-silane couplings.

The development of coupling agents and the ability to attach to different sub-strata are continuously being improved to create new products that cater for a wide spectrum of different minerals. In practice (not only in pavement engineering), it's important to be aware of limitations that do exist in the nano-silane technologies that are commercially available to be used. Both the designer and contractor must ensure that the nano-silane technology specified/used is effective and compatible with the naturally available materials to be treated and stabilised.

\subsubsection{Compatibility of the Nano-Modifier and the Stabilising Agent}

The compatibility of the stabilising agent (bitumen emulsion and/or polymer(s)) with the modifier (alkoxy-silane), is fundamental to the stability and successful application of any emulsion (substance mixed with a carrier fluid). For purposes of discussion, the 
basic properties of bitumen emulsion are used to discuss the influence thereof on the selection of a successful application of an alkoxy-silane modifying agent. Even the most basic differences in bitumen emulsions, i.e., cationic versus anionic, will have an important influence on the stability and performance of any modifying agent added to the emulsion.

Anionic emulsions will only provide a low-risk stable product, ensuring a long shelflife and performance characteristics in combination with an applicable anionic alkoxy-silane and vice versa with cationic emulsions. The combination of non-compatible nano-particles (the emulsifying agent and the nano-silane) will result in either short-term or medium-term problems in terms of stability, separation and/or neutralisation of the nano-particles within the carrier fluid and an ineffective product not useable in practice. Prevention of failures before stabilisation is a design approach based on the understanding of the chemistry of the various nano-particle combinations, together with the mineralogy of the materials to be treated [6]. In the case of an anionic or cationic emulsion, the emulsifying agent determines the main characteristics of the mix at micro level. In order to blend successfully during the modification of the emulsion, the nano-silane also needs to be compatible with the emulsifying agent in order for it to attach firmly to the bitumen molecule.

The modification of the bitumen emulsion through an emulsification process, is required to ensure that the alkoxy-silane is thoroughly distributed throughout the bitumen emulsion. The emulsification process is done at high shear to ensure that the two emulsification agents are well distributed throughout the emulsion and that the bitumen molecules are separated effectively into the smallest possible particle sizes. The manufacturing process should optimise the production of the modified emulsion with a resultant emulsion with a low viscosity and high stability. Unique properties and advantages which will retain its stability and viscosity over periods of months without detrimental effects (as has been shown and proven under actual field conditions [6]) are required [20].

\subsection{Engineering Evaluation of the Effect of Nano-Silicon Modifications}

The engineering evaluation of the effect of the nano-modification of materials using alkoxy-silanes, is determined with practical tests indicative of the required engineering properties. The effect of the treatment and stabilisation of the stone/gravel/soil using the NME is measured in terms of the compressive strength, tensile strength and durability using standard test procedures under dry and wet conditions [9]. These results are compared to minimum specified criteria [6] as an indication of the suitability of stabilised materials for use in the various road pavement layers [6,17]. The effect of the nano-modification will naturally be the difference in test results with and without the modification [21].

It should be noted that in terms of other uses in the built environment, compressive strength measurements are considered the least useful due to the impact of the stone type on compressive strength. In most cases tensile or flexure tests (e.g., 3 point and 4-point bending tests) are considered of greater value and will be more representative of the actual influence of the nano-modification to a stabilising agent [1]. In terms of the use in pavement engineering, the Retained Tensile Strength (RTS) and the Retained Compressive Strength (RCS) (percentage of the wet test compared to the dry test results) has been observed to play a role in the future behaviour of the pavement structure and the resistance of the material to the effect of water and the formation of potholes when exposed and subjected to water [6]. The water-repellent characteristics are of importance both for the evaluation of the durability of the materials during wet and dry cycles, as well as the ability to prevent or at least minimise future weathering due to chemical decomposition within the road pavement structure. It should be noted that the design measurements done under laboratory conditions should be verified during construction to ensure that minimum requirements are been met in the field $[6,20]$. It is recommended that the laboratory requirements in terms of the minimum criteria, be adjusted to take into account the controlled conditions under which such tests are performed. 


\subsection{Cost Aspects Associated with the Use of Nanotechnology-Based Products}

The main objective of implementation and use of new technologies for macro application in the field of road pavement engineering is to meaningfully lower the unit costs of road infrastructure delivery. Nano-silane technologies provide engineers with the ability of neutralising any possible negative effect of secondary minerals that may be present in naturally available materials. In the absent of this ability, the criteria for the use of materials in the upper pavement layers of a road will always be aimed (as has traditionally been the case) the limitation of risk by specifying newly crushed stone (limiting the risk of the presence of secondary minerals) on roads subjected to medium to high traffic loading. Similar trends will also apply to lower order roads, normally specifying at least very good gravel in the upper pavement layers. The traditional ways of materials' use and specification come at a considerable cost associated with the construction of roads. Unit costs that make it impossible for the developing world to, in the foreseeable future, develop paved road networks required for sustainable economic development. A typical example of a cost comparison of a traditional design versus a design using NME stabilisation for a road designed for a relatively low traffic loading, is shown in Figure 7.

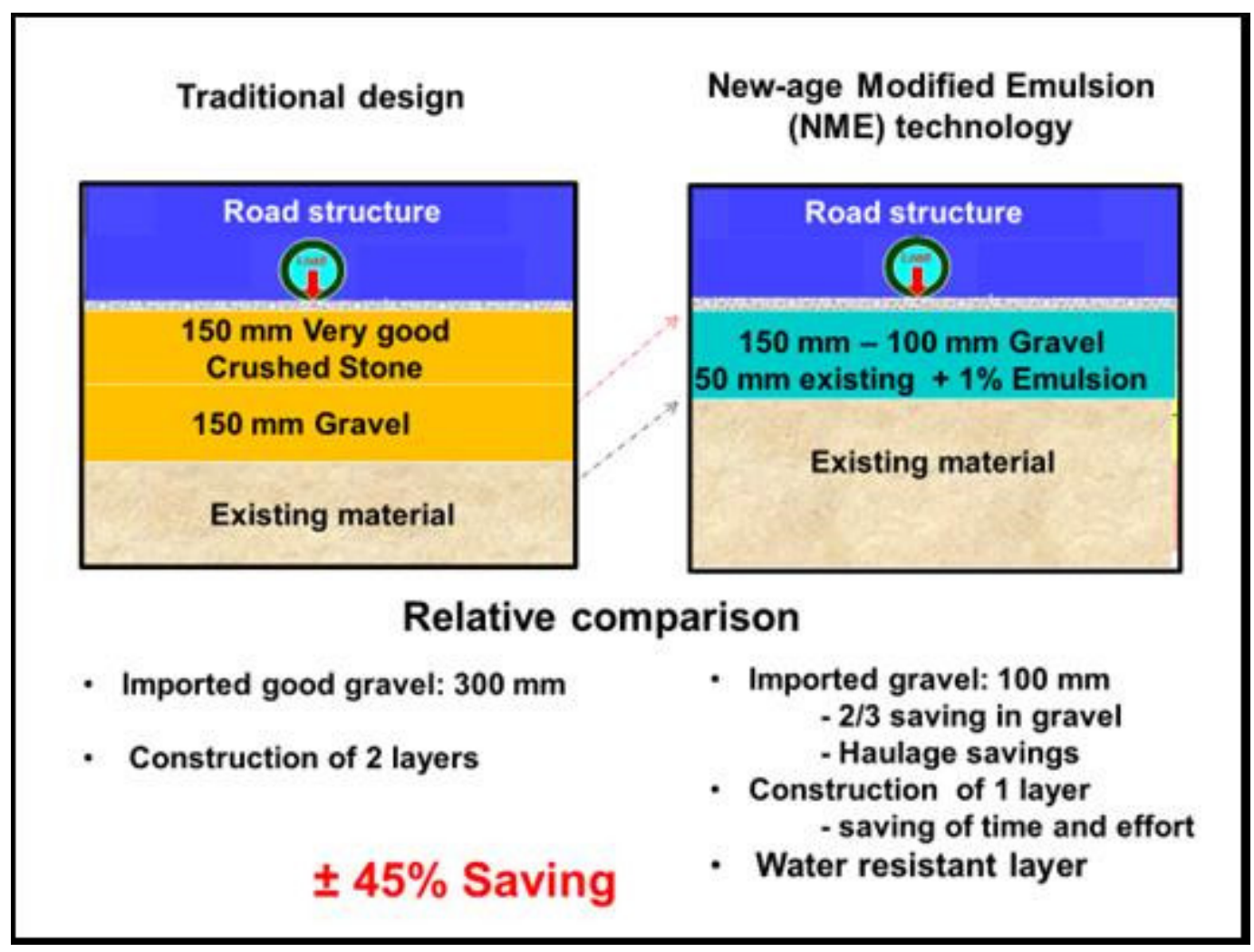

Figure 7. Typical example of a road designed for a relatively low traffic loading, using traditional design methods versus a design incorporating NME stabilisation of naturally available materials.

From Figure 7 it is seen that not only is savings achieved through a reduction of imported material, but also due to savings in construction time and effort. The introduction of a lubricant (e.g., bitumen or equivalent) in the NME stabilising agent, enables the required compaction to be achieved with considerably less effort compared to the use of only water in the compaction of granular material. Stone orientation during compaction is also much better resulting in a smooth surface and good riding quality that impacts on the road user costs.

NME technologies enable material properties to be improved and reduce the risk of premature failures, with special reference to applications in a developing environment where severe challenges with regard to funding and maintenance ability exist. A meaning- 
ful reduction in the life-cycle cost is achieved not only by reducing initial construction costs, but also through the reduction of future in situ weathering of materials (as discussed) and reduced maintenance costs through the limitation of the negative impact of water damage. The cost of NME stabilisation is a function of the unit cost as well as the volume required in order to achieve the required objectives as discussed. Different volumes of the modifying agent may be required using different products in order to meet the minimum engineering requirements (due to various factors, including the particle size of the modifying agent and the chemical composition).

One of the major advantages of nano-scale products is the area versus size benefit (refer Section 4.5). In practice it will be necessary to determine the quantity (volume) of the modifying agent that is required to effectively cover the material that is being treated to meet the specified RTS and RCS engineering specifications. In terms of road pavement engineering, quantities are normally calculated in terms of volume $\left(\mathrm{m}^{3}\right)$ of material that will be processed. Due to differences in the NME stabilising agent properties, some considerable differences in volume may be required to meet the required engineering properties. Hence, it is essential to require potential contractors to provide costing in terms of the cost per cubic meter of material to be stabilised and not the cost per volume (litre) required to achieve the required end result. Per volume (litre) any nano-scale product may be relatively expensive, but due to the small volumes required, it could be considerably less expensive compared to products consisting of micro-size particles, to achieve the required engineering properties per cubic meter stabilised.

In order to successfully stabilise the naturally available material, meeting the minimum engineering requirements, all areas of the different fractions of the material need to be covered by the modifying agent. It may be relatively easy to determine the characteristics of the material in terms of the various fractions by doing a simple sieve analysis. The various fractions of the material are normally measured as standard practice, using sieve sizes varying from 63 to $0.075 \mathrm{~mm}$ and even smaller using generally available laboratory test methods.

The percentages of material passing through and of that retained on a specific sieve size are usually expressed in terms for the percentage of weight of the material used (e.g., $1 \mathrm{~kg}$ ), and the various fractions in terms of generally available sieve seizes to determine the grading of the material. The material fractions will also impact dramatically on the volume of any material required to cover the surface area of the various fractions of the materials to be used. In theory, this can be calculated using Equation (2).

Per unit of the material to be stabilised (e.g., $\mathrm{kg}$ ):

$$
\begin{gathered}
\text { Nano-silane }(\mathrm{kg})= \\
\frac{\sum_{i=0}^{n} \text { surface area of material passing sieve }((\mathrm{i})-(\mathrm{i}+1))\left(\mathrm{m}^{2}\right)}{\text { Nano-silane coating area }\left(\mathrm{m}^{2} / \mathrm{kg}\right)}
\end{gathered}
$$

where:

$\mathrm{i}=$ Sieve sizes normally used to determine the grading of materials varying from $63 \mathrm{~mm}$ to $0.075 \mathrm{~mm}$; when $n=0.075 \mathrm{~mm}$ sieve size, then $n+1=0 \mathrm{~mm}$ (i.e., the surface area of the material passing the $0.075 \mathrm{~mm}$ sieve);

$n=$ number of sieves used to determine the material grading, where the last sieve size, i.e., the $n$th sieve size $=0.075 \mathrm{~mm}$.

In practice, these calculations may prove basically impossible to execute to any degree of accuracy. Although the size of the modifying agent (alkoxy-silane nanoparticles) which are going to attach to the material to be stabilised may be known with a degree of certainty, the scale to which these calculations are done (nano-scale), make the calculations of the area to be covered very difficult, even if the various particle fractions in terms of grading is known. The porosity and texture of the material (stone/aggregate/soil) alone could add a multiplying factor to the area to be covered in terms of nano-surface. In general anormal pavement engineering practice, in terms of smaller fractions, only the percentage 
passing the $0.075 \mathrm{~mm}$ sieve size in terms of normal sieve sizes is measured. The minerals comprising the $0.075 \mathrm{~mm}$ fraction of material may vary from $0.075 \mathrm{~mm}$ (e.g., fine-grained quarzitic particles) to clay crystals (normally considered as less than $2 \mu \mathrm{m}$ ) that may be less than $1 \mathrm{~nm}$ in size.

However, the percentage passing the $0.075 \mathrm{~mm}$ sieve together with the information obtained from the XRD tests of the fraction passing the $0.075 \mathrm{~mm}$ sieve [6], can be used to get an indication of the percentage and the type of the nano-size particles present in the material to be stabilised. This information can form the basis to adjust the amount of alkoxy-silane required to achieve the required hydrophobic action. The mineralogy of the material (from XRD scans) usually also gives an indication of the relative surface area. For the same particle size, the influences of the primary minerals could vary considerably. Table 1 [22] gives an indication of some of the relative surface areas of different materials.

Table 1. Differences in surface area of different materials per unit mass $\left(\mathrm{m}^{2} / \mathrm{g}\right)$ [22].

\begin{tabular}{lc}
\hline Material & Surface Area of Material $\left(\mathbf{m}^{2} / \mathbf{g}\right)$ \\
\hline Glass & $0.1-0.2$ \\
\hline Quartz $\left(\mathrm{SiO}_{2}\right)$ & $1-2$ \\
\hline Calcium silicate $\left(\mathrm{Ca}_{2} \mathrm{O}_{4} \mathrm{Si}\right)$ & 2.6 \\
\hline Calcium carbonate $\left(\mathrm{CaCO}_{3}\right)$ & 5 \\
\hline Clay & 7 \\
\hline Talc & 7 \\
\hline
\end{tabular}

Due to the considerable variation (also in the size of the nano-scale modifying agents), it is important to compare costs on the basis of the volume $\left(\mathrm{m}^{3}\right)$ of the material to be stabilised. The considerable area to size advantage of the use of applicable nano-scale technologies should normally render the cost of alkoxy-silane modifications (which are relatively affordable in terms of available nanotechnologies), to have a minimal influence if the objectives in terms of the use of engineering requirements can be met using naturally available materials.

\section{Conclusions}

Traditional material testing and design approaches aims to specify material characteristics by eliminating or minimising the possible negative effect of the presence of secondary minerals (e.g., clay) on the future performance of a road. This will normally either require the use of thick asphaltic layers and/or the use of freshly crushed stone. These traditional road design practices come at a considerable cost, not affordable to the developing world. The use of material compatible nano-silane products with an applicable stabilising agent, enable engineers to neutralise the presence of any secondary minerals that may be present in naturally available materials. The introduction of these applicable nanotechnologies can considerably reduce the unit cost of the provision of all-weather roads and contribute considerably to economic development in many developing countries of the world. However, without guidelines as to the risk-free testing, assessment, evaluation of the available proven nano-products, the introduction thereof in practice, may result in premature failures when using non-compatible and/or unstable products, resulting in the rejection of applicable nanotechnology solutions by practicing engineers.

Nano-silane technologies have successfully been used in the built environment for more than a century and a half to protect stone buildings against the environment. The lessons learnt in the built environment during the development of effective, applicable nano-silane products, also applies directly to the roads industry. During the early years, scientists tasked with the development of products to protect buildings, discovered through trial and error that the type of stone (primary minerals) and the condition of the stone (secondary minerals) have a major impact on the successful application of a specific 
nano-silicon based product. Of all the products developed over many years, only a few have been proven to contain the properties to enhance material characteristics and neither be harmful to living creatures and the environment.

It follows that the successful introduction of applicable nanotechnologies in the field of pavement engineering need to take cognisance of the available experience from the built environment. Knowledge of primary minerals (type of stone) and the secondary minerals (condition of the stone) and the understanding of the various implications associated with the use of silicon-based nanotechnologies need to be understood and recognised. The development of scientifically based design approaches using the available knowledge was used to successfully test, implement and verify designs using Accelerated Pavement Tests (APT). Depending on various factors, cost savings of at least 30-50 per cent (or more) have been shown to be realistic without compromising the integrity of the road pavement structure.

The identification of the fundamental properties and understanding of the basic science involved in the implementation on applicable, proven nanotechnology are essential to ensure that the technology is successfully implemented. Many products are being marketed under pretence of New-age Modified Emulsions (NME). Road authorities and practicing engineers need to be made aware of the basic requirements needed to ensure that products that can successfully be used with the naturally available materials in any specific area, without any increase in risk. The following fundamental aspects and the evaluation of scientific principles associated with these aspects in the context of road pavement engineering, are crucial to the reduction of risks associated with the introduction of new-age technologies into the roads industry:

- Determining and evaluating toxicology, health and safety issues;

- Evaluating environmental aspects, leaching and possible influences on groundwater;

- Ability of nanotechnology products as a binder;

- Understanding surface area or coverage, versus volume of nano-scale products;

- Stability of nano-particles in combination with a stabilising agent and mixing into a carrier fluid, e.g., construction water;

- Hydrophobic characteristics to be achieved using applicable products to address durability associated aspects of materials;

- Compatibility aspects of nano-silicon modifications to binders that will influence the successful application and use thereof, including;

- Compatibility with the mineralogy of the materials, and

- Compatibility with the stabilising agent to be modified;

- Engineering evaluation of the effect of nano-silicon modifications in terms of required scientific properties (compressive strengths, tensile strengths, durability and stability), and

- Cost aspects associated with the use of nanotechnology solutions in pavement engineering.

The design approach developed on the basis of fundamental scientific principles are universally applicable. The successful introduction of new-age technologies in the provision of macro infrastructure projects, considerably reducing unit costs while reducing associated risks, is only possible through the following of sound scientific principles. Archaic material classification tests and systems need to be substituted through the identification of the minerology of material and the identification of material compatible stabilising agents. The developing world is in urgent need of climate resistant long-lasting affordable road infrastructure. These available nanotechnology solutions could assist to a large extent to address these urgent service delivery needs.

Author Contributions: G.J.J. under the directive of the Head of Department of Civil Engineering, W.J.v.d.M.S., has been leading the research into the provision of affordable road infrastructure at the faculty of Engineering, University of Pretoria. W.J.v.d.M.S. recognized the potential of nanotechnology solution in the field of pavement engineering more than a decade ago. G.J.J., through involvement in 
the private sector and the support of road authorities, has been instrumental in the development of scientific principle, ensuring that implementation can be achieved at a minimum risk. All authors have read and agreed to the published version of the manuscript.

Funding: This research received no external funding.

Institutional Review Board Statement: Not applicable.

Informed Consent Statement: Not applicable.

Data Availability Statement: Not applicable.

Acknowledgments: The support of GeoNANO Technologies (Pty) Ltd., 18 Davies road, Wychwood, Germiston, 1401, South Africa, Tel.: +27844078489, www.geonano.co.za (accessed on 12 February 2021), info@geonano.co.za, in support of students in the Department of Civil Engineering, University of Pretoria, Pretoria, South Africa to test a wide variety of materials as part of final year projects and post-graduate theses, testing the various principles identified in this paper, is acknowledged.

Conflicts of Interest: The authors declare no conflict of interest.

\section{References}

1. Wheeler, G. Alkoxysilanes and the Consolidation of Stone; The Getty Conservation Institute: Los Angeles, CA, USA, 2005.

2. Zhang, S. Material Characterisation Techniques; CRC Press: Boca Raton, FL, USA, 2008; ISBN 1420042947.

3. Steyn, W.J.vdM. Potential Applications of Nanotechnology in Pavement Engineering. J. Transp. Eng. 2009, 135, 764-772. [CrossRef]

4. The Chemical Rubber Company. Handbook of Chemistry and Physics; A Division of the Chemical Rubber Company; CRC Press: Cleveland, OH, USA, 1973.

5. Weinert, H.H. The Natural Road Construction Materials of Southern Africa; National Book Printers: Cape Town, South Africa, 1980.

6. Jordaan, G.J.; Steyn, W.J.vdM. A Comprehensive Guide to the Use of Applicable and Proven Nano-Technologies in the Field of Road Pavement Engineering Design and Construction; Department of Civil Engineering, University of Pretoria: Pretoria, South Africa, 2019; ISBN 978-0-620-83022-5.

7. Rust, F.C.; Akhalwaya, I.; Jordaan, G.J.; Du Plessis, L. Evaluation of a nano-silane-modified emulsion stabilised base and subbase under HVS traffic. In Proceedings of the 12th Conference on Asphalt Pavements for Southern Africa (CAPSA 2019), Sun City, South Africa, 13-16 October 2019.

8. Rust, F.C.; Smit, M.A.; Akhalwaya, I.; Jordaan, G.J.; Du Plessis, L. Evaluation of two nano-silane-modified emulsion stabilised pavements using accelerated pavement testing. Int. J. Pavement Eng. 2020, 1-14. [CrossRef]

9. Jordaan, G.J.; Steyn, W.J.vdM. Testing of granular/soil characteristics for the optimisation of pavement designs using reactive stabilising agents including "new-age" nano-technologies. In Proceedings of the 12th Conference of Asphalt Pavements for Southern Africa (CAPSA 2019), Sun City, South Africa, 13-16 October 2019.

10. Jordaan, G.J. Life-cycle cost analysis-An integral part of pavement rehabilitation design. In Proceedings of the 10th Conference on Asphalt Pavements for Southern Africa (CAPSA 2011), Drakensberg, South Africa, 11-14 September 2011.

11. Brown, R. A brief account of microscopical observations on the particles contained in the pollen of plants and on the existence of active molecules in organic and inorganic bodies. In Edinburgh New Philosophical Journal; Longman, Orme, Brown \& Longmans: London, UK, 1828; pp. 358-371.

12. Einstein, A. Über die von der molekularkinetischen Theorie der Wärme geforderte Bewegung von in ruhenden Flüssigkeiten suspendierten Teilchen. Ann. der Phys. 1905, 322, 549-560. [CrossRef]

13. Creative Commons (cc), Plaatje om te Illustreren dat $1 \mathrm{~kg}$ van Deeltjes van $1 \mathrm{~mm}^{3}$ Eenzelfde Oppervlak Hebben als $1 \mathrm{mg}$ van Deeltjes met $1 \mathrm{~nm}^{3}$. Available online: Creativecommons.org; www.commons.wikimedia.org/wiki/User:Wouterhagens (accessed on 14 February 2021).

14. Adamson, A.W. Physical Chemistry of Surfaces, 3rd ed.; John Wiley \& Sons: New York, NY, USA, 1976; pp. 9-10.

15. GeoNANO Technologies (Pty) Ltd. Photographs; GeoNANO Technologies (Pty) Ltd.: Germiston, South Africa, 2016.

16. Jordaan, G.J.; Kilian, A. The cost-effective upgrading, preservation and rehabilitation of roads-Optimising the use of available technologies. In Proceedings of the 2016 Southern Africa Transportation Conference (SATC 2016), Pretoria, South Africa, 4-7 July 2016.

17. Jordaan, G.J.; Kilian, A.; Du Plessis, L.; Murphy, M. The development of cost-effective pavement design approaches using mineralogy tests with new nano-technology modifications of materials. In Proceedings of the 2017 Southern Africa Transportation Conference (SATC 2017), Pretoria, South Africa, 10-13 July 2017.

18. Laurie, A.P. The Painter's Methods and Materials; Dover Publications: New York, NY, USA, 1926.

19. Weiss, N.R.; Slavid, I.; Wheeler, G. Development and assessment of a conversion treatment for calcareous stone. In Proceedings of the Ninth International Congress on Deterioration and Conservation of Stone, Venice, Italy, 19-24 June 2000; Volume 2, pp. 533-540.

20. Jordaan, G.J.; Kilian, A.; Muthivelli, N.; Dlamini, D. Practical Application of Nano-technology in Roads in southern Africa. In Proceedings of the 8th Transportation Technology Transfer (T2) Conference, Lusaka, Zambia, 8-10 May 2017. 
21. Akhalwaya, I.; Rust, F.C. Laboratory evaluation of road construction materials enhanced with nano-modified emulsions (NME). In Proceedings of the 2018 Southern African Transportation Conference (SATC'18), Pretoria, South Africa, 9-12 July 2018.

22. Power Chemical Corporation (PCC). Silane Coupling Agents Guide; PCC: Nanjing, China, 2009. 